Volume: 11 Issue: 1 Year: 2014

\title{
New emerging Ahiskan Turk ethnic identity in the United States
}

\author{
Sebahattin Ziyanak ${ }^{1}$
}

\begin{abstract}
This aim of this research paper is to provide an understanding of the themes of citizenship and identity in the context of migratory flows of Ahiskan Turks from Russia, both within the region and beyond. Moreover, by choosing the theme of identity, I hoped to bring to the discussion, the idea of the multiplicity of identity, which the individual may carry, with all the concomitant implications this has for the concept of local and national boundaries. This research raised a number of questions, such as "how do individuals or groups with a Russian Ahiskan Turk heritage perceive themselves and others? And how do flows of people affect one's process of identity formation? To address these issues, I tracked the perspectives of various migrants who began moving from Russia to the United States in 2004. Within seven years after achieving refugee status, several obtained a green card, followed by US citizenship. In this paper I have elaborated on their settlement processes, and related conditions and their issues and concerns. In response to these observations, I describe how these recent migrants are related to their host countries/communities and how the host countries/communities are related to them. Finally, this research project also attempts to contribute towards the understanding of how immigrants interact with national narratives, and other immigrant groups, and how they define themselves.
\end{abstract}

Keywords: Ahiskan Turks; US citizenship; ethnic minorities; Russian citizenship; Raindrop Turkish Foundation

\section{Introduction}

I knew nothing about the conditions of refugees and immigrants living in America until I started to volunteer part time at the Refugee Center and Raindrop Foundation. Through my volunteering and spending more time with a variety of migrants, I began to better understand how immigration and ethnicity are inextricably linked to social-economic, political, and cultural processes.

In order to achieve sufficient depth to my exploration, I began keeping interview records of my field notes. Since there were many subjects to visit, I figured I would only interview those refugees I

\footnotetext{
${ }^{1}$ Ph.D., University of North Texas, sebahattinziyanak@yahoo.com
} 
observed with the new rig. Moreover, it would simply take too long to compile all the notes I had taken. Thereby, I elected to conduct short interviews with selected individuals or organizations.

I wanted to make this field research a little different in that it would have enough pictures to help confirm any observation, etc. I knew I would need those resources from "growing up" in this lifestyle. I observed hundreds of subjects but just could not find the time to interview all of them. Over time, I started to get to know 71 participants while coming together at social events, hanging out with them, giving them directives as needed and so on. I wanted to produce a report that would investigate how a typical refugee lives, how they appear, and how they think about their identity.

\section{Literature Review}

The process of constructing and reconstructing identity both theoretically and empirically is problematic and complex (Benyamor \& Skotness, 1994). The same ideas pertain to people who have an Ahiskan Turk ethnic identity. Through examining the encounters of the Ahiskan Turks as they processed their US citizenship status, this research highlights the importance of the Ahiskan Turk ethnicity. Currently, this community comfortably expresses their own ethnic identity and also adopts the culture of the US. In exploring the Ahiskan Turks' identity and citizenship processes, it was hoped this research would reveal how often cultural identities are sustained in the US.

It is important to note that Meskhetian and Ahıskan Turks are the same ethnic group. However, people mostly prefer to call themselves Ahiskan Turks, underlying their Turkish roots. However, Aydingun (1999) notes that the term Meskhetian is highly cited in the international literature.

In order to achieve a better perspective of the Ahiskan Turk identity, this research also investigated the structure and conditions of these people back in their homeland of Russia. Pilkington (1998) posits that character of the migration regime in the home country, in this case Russia, is the key that helps to identify migration processes. Pilkington (1998) places her emphasis on the emerging dominant themes in society.

There is a huge gap in the literature however, about the Ahiskan Turks in the United States. I have not found any single piece of information related to this new ethnic group even though they have been living in the US since 2004. However, before 2004, some literature was available and explained the importance of local Ahiskan identities of kin, social and economic class and religion (Aydingun 1999 \& Khazanov 1992; Zeyrek, 1995). Nevertheless, these literature sources do not illuminate anything about the Ahiska Turks ethnic groups' contemporary order. According to my personal observations and interviews with members of this ethnic group, people feel at home and for the 
Ziyanak, S. (2014). New emerging Ahiskan Turk ethnic identity in the United States. International Journal of Human Sciences, 11(1), 688-699. doi: 10.14687/ijhs.v11i1.2779

first time have gained citizenship of a country. Now they belong to a nation at least due to their citizenship.

The Ahiskan ethnic identity was first generated in the early 1800s. Since that time, maintaining the Ahiskan identity has been the main priority of this group rather than a symbol of ethnicity. Water (1990) claims that "an ethnic identity is something that does not affect much in everyday life" (p. 147). She continues to state that ethnic identity is not a determining factor of your life style, employment, your neighborhood and so on (Water, 1990). However, this definition was not sufficiently congruent for describing the Ahiskan identity during certain periods of their association with Russia. Having an Ahiskan ethnic identity and being labeled as lacking citizenship caused contradictory desires and inconveniences for this ethnic group although language was not a concern for them. Through a period where they were subject to social pressure and unconformity in achieving individual rights, ethnic labeling shaped their neighborhoods, relationships, and life styles. During that period, cultural and ethnic differences also provided support for discrimination.

The Ahiskan Turks I describe in this research live very close to each other, and isolation is not possible in the part of the community where they live. An Ahiskan identity provides a member with common feelings and individuals are highly aware of their ethnic consciousness. There is no challenge to traditional values or traditional ties. In contrast, American life takes place in conformity with individuality. How they fit in the America culture is so far-very well. They are nurtured by the benefits of the American culture.

The Ahiskan Turks ethnic identity is a reconstructed one and it finds its creation in language and in the American culture in general, especially in the case of the young generation who specifically accept English as their native language along with their rapid adaptation to its culture. McCormack (2002) presumes that speaking diverse languages is more acceptable and common to today's world than was the case previously. The offspring of Ahiskans speak at least four languages, including English, Russian, Turkish, and Uzbek.

With respect to ethnic minorities in United States, the adaptation process of the immigrant takes place over different time periods, but normally takes a longer rather than a shorter timeframe. Freeman (1999) explains the difficulties with respect to the adaptation of migrants at the social level and through all social phrases. However, amazingly the change and adaptation process for the Ahiskan ethnic groups has been successfully managed in the context of American social life. This ethnic group considers the United States is their new home, and that it more diverse, hybrid and different from their former home. These factors strengthen their ethnic identities. 
Ziyanak, S. (2014). New emerging Ahiskan Turk ethnic identity in the United States. International Journal of Human Sciences, 11(1), 688-699. doi: 10.14687/ijhs.v11i1.2779

Cultural and ethnic differences are significantly recognized by this ethnic group as well, and the major argument is how they identify themselves. They characterize themselves according to their religion, Turkish heritage, and country of citizenship. According to Stuart (1993) two kinds of identity reside in identity formation. The pursuit of unity and commonality comprise the first identity type. The second type is the process of identification of becoming, which reveals an ongoing process, but results in one not completely owning the host identity. Within a short time, this ethnic groups' success in the business ownership such as opening restaurants, body and mechanical shops, exporting vehicles to Russia and other Turkic countries, and engaging in the truck business shows that they are adapting to the culture at a significant level.

According to Benyamor and Skotness (1994) two decades ago, in the early 1990s, social identity became a fundamental problem in the context of migration. The problems that stem from migration today seem consistent for this ethnic group as well. On the other hand, power, status and integrity are important. Besides that, the Ahiskan ethnic groups were familiar with these problems in their previous settlements. Pilkington touches on the identity problem by illustrating the disembodiment of Russia. The place where you were born, where your children were born, and where you will be buried is seen as problematic (Pilkington, 1998).

After the collapse of communism in the USSR in 1989, a new form of ethnic religious and national formation occurred in the region (Rutherford, 1990). The outcome of the resulting complex conditions and political fights of those opposed to the Russian government were still not adequate to legitimize the Ahiskan identity in Russia, but reinforced the ethnic sentiments that existed within the Ahiskan community. Waters (1990) supports the idea of the importance of ethnic 'specialness' that can bolster the collective consciousness of an ethnic community.

The dominant ethnic consciousness in this case brought about the acknowledgement of the importance of the Ahiskan history as a form of ethnic group identity. Tradition and community are also said to be strongly tied to the process of maintaining one's religious values. According to Yucel (2003), history and religion have certain common elements and can provide common denominators for some communities. Within this context, the Ahiskan ethnic groups are united through their historical ties and their increased collective identity. Therefore, there is no emerging conflict among this group between their individual and overall community identity perceptions.

The experience of calling Black in Russia and distinguished as white in the United States has however appalled the Ahiskan Turks. The acceptance of their being white at least as far as appearances goes cannot be considered terribly different from the immigration process of others. Although according to Nee (2003) experiencing difficulty in the immigration process is the same at 

11(1), 688-699. doi: 10.14687/ijhs.v11i1.2779

some level, and Nee asserts that most of the descendants of today's Hispanic, Asian, and other newcomers are treated "in much the same way as the children and grandchildren of the European immigration" who experienced difficulties (Nee, 2003). Within this context, the Ahiskan ethnic group has experienced the same processes experienced by other newcomers. As opposed to Nee's idea, this ethnic group has however, created considerable economic power for themselves in a very short period. In addition, they are not undergoing the experience of being black as experienced in Russia.

Finally, establishing organizations in the neighborhood has been given much attention by this ethnic group. Detroit, Seattle, Houston and Dallas are examples of this. In Dallas many of the members of this group moved to Seattle to settle so they could be close to their relatives. Lumping is thus the common characteristic within this ethnic group. As of today there are only three families left in the DFW area. Faber (2002) asserts that an organizations identity is supported through internal and external stories which make the lumping group more consistent and productive.

\section{Methods}

This research focused on discovering and/or on understanding how refugees determine themselves. I hoped to gain a better perspective on the individual's past and current circumstances. In order to achieve this goal, people were interviewed and observed to obtain the desired data for the current research. All interviews were conducted in the respondent's homes.

I interviewed families and sponsors who organized and helped the subjects who were immigrants. Participants ranged in ages from 17 to 83 . Interviews lasted about three hours, and some of them were also video or tape-recorded. During the interviews, I transcribed these word for word, and included responses to probe questions that were added to the structured interview questions and altered as required throughout the data collection process. While acquiring the data, I also noted down some relevant details in a journal. Some parts of the interviews were also filmed. The files were written up immediately after the interviews were concluded. Some of them were written on a lap top without any delay.

The interviews began with the following question: "Can you introduce yourself?", "How do you see yourself?' These questions were used to help explore their definitions about identity.

This was followed by a long series of choice questions in which the subject was asked about a variety of specific aspects of her/his life such as money, transportation, housing, neighborhood and safety. Part of the interview also explored the adequacy of the subjects housing situation using 

11(1), 688-699. doi: 10.14687/ijhs.v11i1.2779

a series of questions that probed some of their specific conditions, such as "how would you support yourself" or "do you feel yourself safe here"?

Data analysis using constant comparison techniques involves comparing and contrasting among multiple events, meanings, and perspectives by constructing multiple codes and categories to help the researcher to break through assumptions and to uncover specific dimensions (Warren \& Karner, 2004). For example, one of the questions, which "Do you want to live in the US permanently", was posed in order to explore the subjects' preferences and thoughts.

I took a different approach to transcribing the conversation, because starting, stopping, and rewinding the cassette file took an extraordinary amount of time. Basically, I went through the audio, took down what I could and filled in the gaps on a second round of listening/typing. I also brought my laptop with me. I started writing at the same time as the subjects spoke. This took about three hours.

\section{Findings and Results}

People do not plan on becoming refugees. This situation may occur however, as a result of an unexpected offer by the US government, as well as by peoples' own personal choices. The following were some reasons that led to the interviewees journeys to the US. First, some of these refugees were not eligible to obtain an ID from their home state or make a deposit in the bank or open an account in Russia. Some were evicted or displaced from their homes and therefore migrated to the United States. Besides that, many expressed personal reasons as well.

Interviewer; why did Ahmet come to the US and not to Turkey?

Ahmad; “Turkey didn't invite us," he says, “and we don't have passports. We came to the US as refugees. We wanted to go to Turkey but how could we get there? It's a very complicated political issue." (1st interview with Ahmad Mazmanov)

Coming to the US is widely accepted as feasible by many people of Turkish heritage in Russia since many have been through experiences such as, relationship breakdowns, misuse, forced exiles from their homes, and unemployment.

Interviewer; did he envision any possibility of a future for them in Russia?

Ahmet now has two children: Ceylan aged ten, and Tamara, aged seven. he says. "For them, there was no future. It was not created for us in Russia,".

I found the subjects may call themselves newcomers, immigrants, refugees, or American. or they may still strongly identify themselves with the country of origin. However, regardless of how they chose to identify themselves, or whether they wanted to call themselves a pioneer, or not, depended 

11(1), 688-699. doi: 10.14687/ijhs.v11i1.2779

on their willingness to generate new thoughts and actions. Believing, thinking and acting as they did in their country of origin may or may not have any use in the United States. One's willingness to accept, adapt and change will greatly determine one's ability to attain the "better life" they came to find.

\section{The Construction of Turkish Ahiskan Ethnicity}

Regarding the historical Ahiskan Turk identity; (these people had been without a homeland and without any rights for years). I thus examined some information about their history to better understand who considers himself an Ahiskan, also known as a Meshetian Turk. The repatriation of Meshetian became a political issue, involving different parties in and outside Georgia, in Russia and Turkey. These people involved were referred to as Meshetian Turks, Ahiska Turkleri, Muslim Meshetian, or Muslim Georgians from Meskheti

This meant that only the local Georgians, but not the Meshetians, could enter there as there was a passport requirement. Each passport depicted the person's nationality (Aydingun, 1999), and the border guards, looking at the passports could recognize the Meshetian at once and refused them visa entry.

"So what could we do," continues Ahmet. "For fifty years, we're struggling with this issue. What do they have to be afraid of us, making these statements? If (a Russian) says something like that in public, everybody is going to agree with him."

In 1993, the Soviet Union collapsed. The newly formed Russian government at first promised that any citizen who had been living on Russian territory prior to 1993 would be granted Russian citizenship, except for the Ahiskans, "I expected to get a Russian passport," says Ahmet. "We negotiated, argued, and discussed this with the head of the Police Department, with the office of the mayor (of Krasnador). We knocked at every door but they were all locked. Tedorov Server was the leader of the Ahiskan community in Krasnador. He went to Moscow in an attempt to obtain Russian passports for his people; he met with failure". Facing a similar fate under the Soviet leader Joseph Stalin, Ahiskan Muslims fled to Uzbekistan in 1944 (Aydingun, 1999).

\section{Religious Identity and Migration}

Migration processes throughout the world have been changing along with the image host societies have of themselves, some of which have been realizing that at times of fierce conflicts they themselves are turning into multicultural and multireligious societies. Considerable changes can be seen in the self-image of religious communities as well. 
Ziyanak, S. (2014). New emerging Ahiskan Turk ethnic identity in the United States. International Journal of Human Sciences, 11(1), 688-699. doi: 10.14687/ijhs.v11i1.2779

It is thus no surprise then that this fact leads to irritations and disputes within religious communities. The multiplicity of religions is experienced anew through migration processes, both by religious minorities as well as by the major host religious communities, which react to these experiences partly with fundamentalist isolation and partly with ecumenical openings. This can end up in a crisis, in a renewal, or in a deliberate passing over into the other religious world.

The processes described above do not remain without consequence for the function of religion in the society. It is conceivable that new concepts and structures have a reactive effect on those countries where the minority religious communities hail from. Against this background, I raised the question of the transformation of the religious identity of the subjects in the context of migration processes throughout the world.

What about Muslim identity? How did that work in Russia?

Interviewer; was there anyone he knew in the Turkish community who was "religious" (in the public sense)?

Ahmed says he knew of one man who used to pray (the required) five times a day but adds this man was very unusual in the community. "We did not have the opportunity to organize a religious community," he says. In addition, it appears that Ahmet and his family did not fast during Ramadan until quite recently.

Ahkmed says" If you ask me today, who am I, I will say American. But I will never surrender my religion and my Turkish culture. "He also added. "My kids can be American but I want them to have their Turkish culture and Muslim identity. In America, I don't want them to forget how we sacrificed for our culture." His statement seems to end the discussion on identity.

Even if emigration to America seemed, in the beginning, to benefit them, health problems and others often worsened. Even if they have medication, they do not like the situation they have experienced.

Ata Goganadze told me about a visit made to a dentist. He didn't have problem with his teeth, but the dentist pulled out his two teeth and filled some of them." He complained to me that when he went there he had signed some paper that he didn't understand. There was nothing to do except change the dentist.

They call their neighborhood, not America, but Africa. They call African immigrants and African Americans or blacks "kara senlik", which means black festivity and does not mean to hurt a black's feeling. They get along with the black community, but they still keep their children away from them. They are aware of danger in the neighborhood. I had witnessed two immigrants that were shot by 
other refugees or black gangs. Fighting in the neighborhood is not odd. In the neighborhood, a majority of the immigrants are black, and come from Ethiopia and Somali.

Generational problems have also emerged due to the difficulties that the immigrant culture has in adjusting to the new environment. They live in a black community. They have never seen black people before they entered the US.

Another conflict is their attitude against women working. They do not like to see women working, but this is not an option. When a man cannot find a job, the woman has to become the breadwinner of house. However, a woman might quit her job because of fewer hours of work or because the man finds a better paying job. This becomes the main cause of many family arguments. Women, who work mainly in clothing, packing, candy and artificial flower factories, are not allowed to use even the smallest part of the money they have earned, or to enjoy basic freedoms. Change here might not occur without a redistribution of power within the family.

This research study covers the period between the start of the Turk Ahiskan emigration to the United States and the present time. When the Ahiskans arrived in America, they were barely able to communicate among themselves; and other people in other regions were considered strangers.

Manzure Rasulov, cried and did not want to go out for a week

\section{Food} because of the housing condition.

I shall begin with a few examples of how immigrants ate at home. First of all they had breakfast every day: coffee or chocolate Turkish cookies; meat, salad, bread, and fruit for lunch; hinkal (manti), stuffed peppers, bread and fruit for dinner.

\section{The Current Situation}

But soon the reality sets in-the first glance. Probably the first year in America is one of the toughest, emotionally, financially, and physically. By now, the newcomer could have experienced rudeness, would have struggled to find work, would often have put on weight from American food, would have realized the difficulty of trying to communicate without fluency in English, and would definitely have experienced episodes of loneliness and even depression. After two years, a 73 year old Murat and his disabled wife could not adapt to the life in US and returned to Russia. The original relationships established in America could become more distant. The anticipations from relatives back home, that instant success can be achieved in America, could create additional pressures. After emerging traumatized and suffering depression, Fahreddin who is married and has three children tried to commit suicide twice. 
Ziyanak, S. (2014). New emerging Ahiskan Turk ethnic identity in the United States. International Journal of Human Sciences, 11(1), 688-699. doi: $10.14687 /$ ijhs.v11i1.2779

\section{Language}

For many immigrants, the language barrier is naturally very difficult to overcome. But probably the biggest barrier is a psychological one. You can truly feel alone here in America. You have left all your friends, family, and the streets that you are accustomed to, that make up the "system". According to the respondents, everything is different here, such as the customs, traditions, beliefs, and behaviors. You have to make big changes in the way you think and act.

\section{What's changed in before and after?}

What does the newcomer start noticing about America? When they first arrive here, their sponsors or relatives, and friends helped them at first, but this was a temporary concern. Now they can maintain their own lives successfully. As a result of their first experiences, they realized life in the US was not as they expected it to be or as they had dreamed about. In fact, their huge expectations did not make sense so that there were more questions than answers.

\section{Adaptation process}

Two brothers Halil and Celil had a difficult time in the school. They were teased since they could not speak English well. They thought that they did not fit in. They want to be like any other American child, but their parents want to raise their offspring as Ahiskan children. Over time, their offspring adapted to their new environment by learning English, receiving good grades in school, and by making friends. An 18 year old college student Ilyas Goganadze said "Nothing was easy".

\section{What does being American mean?;}

"One cannot be an American by going about saying that one is an American. It is necessary to feel America, like America, love America and then work." (Ensar Rasulov)

They consider that no country is perfect. But in spite of America's imperfections, to them America is still the one country in the world where an individual can accomplish their dreams. As of today, immigrants have advanced despite many mentioned obstacles.

"I came here to win. This is my new home". (Muhiddin Goganadze ). Muhiddin Goganadze also says: “...when I wake up every morning I say—Thank God I'm here." I have found work here, and I have started a very satisfying new life.

\section{Conclusion}

What I have been observing in the migration literature and by interviewing migrants is somewhat of a mystery. Societies today are increasingly characterized by their ethnic, racial, and religious diversity. One key question raised by the global migration of people is how they do or do not come to be incorporated into their new social environments. For over a century, assimilation has been the 
concept used in explaining the processes of immigrant incorporation into a new society. Assimilation has confronted many scholarly challenges as a result of many particular political agendas.

The present migration outcome is possibly due to the fact, transnational relationships have remained an essential element of Turk ethnic communities. The community's ties with the home country (Russia) had in fact been developing for over a century, bypassing the nation state, connecting local sites on two sides of the ocean. Disliking having to change and anglicize their names, these recent Ahiskan migrants are proud Americans, however, they are also proud of their Turkish heritage. Thereby, their situation appears to be one of integration. It is too early to call it assimilation. They are strongly tied to their ethnicity. It is congruent to say that they are in the process of becoming one big culture.

This paper shows that today's immigrants and their situations are different from those of former times since the Ahiskan Turks are presently not ashamed of their origins. They are very comfortable to speak Russian at home. Women generally earn less than men. Newcomers to rental apartments, immigrants and refugees, are often required to rent apartments that they cannot afford. Teenagers and offspring who live in the culture are more likely to become adjusted and integrated than their parents.

Both public agencies and many non-profit organizations, such as IM (Interfaith Ministries,) the RDF (Raindrop Turkish Foundation), and Catholic Charities, provide support to refugees by finding them permanent jobs and providing a variety of social supports. Time will show to what extent they have adapted into the American culture. Further research should thus track their success stories and how they have become white in this country of America.

\section{References}

Aydingun, B. A. (1999). A Deported Nationality: THE AHISKA TURKS. Perceptions Journal of International Affairs. Volume III. Number 4.

Albert, S. and Whetten, D.A. (1985). Organizational identity. In L.L. Cummings and B.M. Staw (Eds.).

Benmayor, R, and Skotnes, A. (1994). Migration and Identity. Oxford University Press.

Brenton, D. F. (2002). Community Action and Organizational Change: Image, Narrative, Identity. English Scholarly Book Inc.

Bozdağlioğlu, Y. (2003). Turkish Foreign Policy and Turkish Identity. Routledge New York \& London.

Carol A.B. Warren and Karner T. X. 2004 Qualitative Research : Field Methods, Interviews, Image and Text. Roxbury Publishing Company. 

11(1), 688-699. doi: 10.14687/ijhs.v11i1.2779

Freeman, S., F. (1999). "Identity Maintenance and Adaptation: a Multilevel Analysis of Response “. Hall, S. (1993). Cultural Identity and Diaspora. In Williams, Patrick \& Laura Chrisman eds.

Hart, V. (1993). Writing a national identity : political, economic, and cultural perspectives New York, USA, , St. Martin's Press.

Khazanov, A. (1992). Meskhetian Turks in Search of Self-identity. Central Asian Survey, Vol. 11, No. 4, 1992.

Mccormack, B. (2002). "Post colonialism in an Age of Globalization: Opening International Relations Theory to Identities in Movement" Journal article; Alternatives: Global, Local, Political, review, Vol. 27.

Pilkington, H. (1998). Migration, Displacement, and Identity in Post-Soviet Russia. Routledge.

Richard, A. and Nee. V. (2003). Remaking the American Mainstream: Assimilation and Contemporary Immigration. Cambridge, Harvard University Press.

Rutherford, J. (1990). A Place Called Home: Identity and the Culture Politics of Difference. London.

Zeyrek, Y. (1995). Dünden Bugüne Ahıska Türklügü, Türk Federasyon Yayınları, No. 2, Frankfurt. 